\title{
Building and Application of Project Regulation Objective System Based on Multi-barrel Model
}

\author{
Meiling Chen ${ }^{1,2, a}$, Cheng Song ${ }^{2, b}$ and Xiaolin Dong, 2, c \\ ${ }^{1}$ School of Civil Engineering, Chang'an University, Xi'an 710064, China \\ ${ }^{2}$ Environmental Economics and Management Institute, Chang'an University, Xi'an 710064, China \\ a1351033674@qq.com, b25323851@qq.com, c1428113356@qq.com
}

\begin{abstract}
By researching the status quo of the project management objectives (quality, schedule and cost) at present, it is found that safety, green and risk management goals are neglected which are important part of project management objectives system. Considering the six objectives and monitoring systems synthetically and using Multi-barrel model, Project Regulation Objective System is constructed to improve the overall quality of project and achieve optimal management. Taking Xi-Tong highway as the research object, verify science of this model, and the results of application of the whole project show that Project Regulation Objective System constituted by quality, schedule, cost, safety, green and risk regulation objective and monitoring systems is effective and science.
\end{abstract}

Keywords: project regulation; six regulation objectives; Multi-barrel model; system.

\section{Introduction}

As the expanding of construction market in China, research on project management theory and project practice continues deepening, and research on quality, schedule, cost three management objectives has been relatively mature. Present, three management objectives have been unable to meet the society requirements due to increasingly heavy construction tasks, constantly expanded projects, increasingly stringent green requirements, increasing project risk and increasingly high requirements of integrated management level. Therefore, in order to achieve scientific, standardized and optimal project management and build a sound project management system, Project Management Objective System should be added safety, green, risk management objective. This study analyzes the limitations of three traditional management objectives and complements the safety, green, risk management objectives in Project Management Objective System. In addition, the implements of six management objectives need corresponding monitoring systems, so six management objectives correspond to the six regulation objectives. Therefore, this study analyzes the relationship among the six regulation objectives and build Project Regulation Objective System based on Multi-barrel Model which includes project management system and monitoring systems.

\section{Analysis of Project Management Objectives Based on Multi-barrel Model}

Project management refers to that people ensure the smooth progress of project and comprehensive coordination and optimization of project objectives by decision-making, planning, organizing, directing, coordinating and controlling project effectively in the life cycle of the project. Objectives of project management are not isolated, but interrelated and bounded tightly. Negligence of a management objective will cause a decline in the overall management level. This principle is equivalent to that barrel's volume does not depend on the longest plank, but the shortest plank.

\subsection{Barrel Model and Multi-barrel Model}

(1) Barrel Model

The core idea of Barrel Model is that the shortest plank which restricts capacity of the barrel plays a vital role [1].For project management objectives, Barrel Model is interpreted as that the ability to achieve one management objective depends on the worst part of internal indicators of objectives. For Project Management Objective System, Barrel Model is interpreted as that the level of management depends on the worst part of multiple objectives. 
(2)Multi-barrel Model

Multi-barrel Model is composed of a plurality of sheets which is itself a barrel and formed the structure of "barrel barrel". Its core idea is that water capacity of big barrel depends on small barrel whose water capacity is the smallest, and water capacity of small barrel depends on its shortest barrel sheet.

Barrel Model can explain the correlation between a single index and the objective, and also the correlation between a single objective and management system. For multi-objective management, defects of Barrel Model is that specific requirements of multiple project management objectives are not uniform and equivalent, but single Barrel Model assumes that its interior is uniform[2]. Single Barrel Model cannot explain the internal composition of multiple objectives, the link between multiple objectives and the relationship between a single objective and the objective system. But Multi-barrel Model can compensate for this defect and evaluation contribution and impact of the six management objectives to overall management level scientifically. In the Project Management Objective System, Multi-barrel Model is interpreted as Project Management System whose management level depends on worst management objective, and the management level of a single objective depends on the worst part of the internal index.

\subsection{Traditional Project Management Objectives and Perfection}

Currently, research on quality, schedule, cost management objective is mature relatively [3-5], and research on safety, green management objectives carried out gradually [6-8]. Three traditional project management objectives require managing project comprehensively within a limited period, standardized quality and stipulated costs. Nowadays, characteristics of the project is large-scale, long duration, more open field construction, more altitude operations, mobility, serious environmental impact, sophisticated construction technology, numerous participation and increasing social factors etc.. As a result, insecurity is increasing, environmental issues become increasingly significant, risks are increasing in project. Especially resettlement compensation, destruction of the living environment and traditional culture and its impact on vulnerable groups which are caused by the project construction easy to increase the probability of a larger social problem whose social impact range large and duration long. At the same time, various safety, environmental and social risks come along with it [9]. But the three traditional management objectives cannot manage security, protect environment and control risk effectively, and have a significant impact on the quality, schedule and cost.

In summary, there are still significant limitations in current three project management objectives. Quality, schedule, cost objective cannot meet the requirements of modern project management, and it should increase the safety, green, risk management objective to perfect Project Management Objective System.

Safety objective is the protection of life, health and property which relates to the smooth progress of the project, so safety objective is an important guarantee for the successful completion of project. Green objective is the requirement of protecting natural and social environment which relates to the harmony of project with the surrounding environment, so green objective is the fundamental of project construction. Risk objective is to prevent possible risks and emergencies in terms of economy, nature and society, so risk objective is an important basis for the management system.

Therefore, in order to perfect Barrel Model of project management objectives, it need additional objective barrel (safety, green and risk objective). Project Management Objective System (showed in Figure 1.) should be a "barrel barrel" Multi-barrel Model. Vat refers to Project Management Objective System, and its internal structure is composed by six objective kegs, including three traditional management objectives as well as safety, green and risk objective. Six objectives which form "barrel barrel" model showed in Figure 1 contacts organically and influences mutually. They are not only part of the vat of Project Management Objective System, but also formed a close attachment relationship with the vat. 

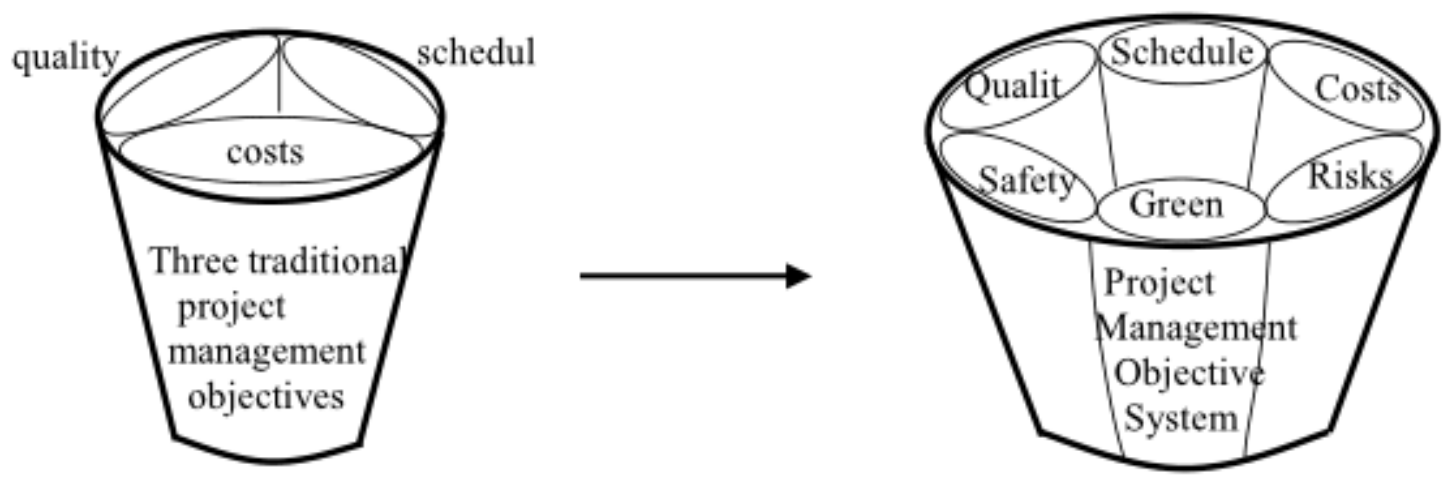

Fig. 1 Multi-barrel Model of Project Management Objective System

\section{Construction of Project Regulation Objective System Based on Multi-barrel Model}

There is a dialectical unity among quality, schedule, cost, safety, green, risk management objective in project management. They cooperate and supervise mutually and exert maximize management efficiency of project. At the same time, it requires strong oversight system which guarantees the six objectives to achieve. Six management objectives correspond to the six regulation objectives. Management and regulation content of each objective is different. Hence, it needs to introduce Multi-barrel Model and build Project Regulation Objective System.

\subsection{Relationship Analysis Among Each Objective in Project Regulation Objective System}

Project management has six objectives. Accordingly, project regulation has six objectives (quality, schedule, cost, safety, green, risk regulation objective). Each objective is interrelated and influences each other. Quality, schedule, cost, safety, green, risk regulation objective is not exist in isolation. Change of one objective lead to changes in other objectives inevitably. It should ensure a balanced and rational relationship among various objectives in project regulation. It is one-sided to emphasize a single goal.

(1)Project Quality Regulation Objective is a Key

The purpose of project regulation is to prevent risk, manage security and realize green construction within the prescribed period and limited funds, and finally obtain standard quality. Good quality control can reduce rework rate, ensure progress, save costs, reduce security risks, improve energy efficiency and reduce the number of risks.

(2)Project Schedule Regulation Objective is the Main Line

All work of project implements during construction process. That is, all work of project implements followed the main line of progress of the project. Effective schedule regulation can ensure the implementation duration of the construction processes, ensure quality, cut costs caused by rework and extension, operate safely and orderly, deal with pollution timely and reduce the incidence of risk.

(3)Project Cost Regulation Objective is the Requirement

Construction costs are determined according to specifications, standards, norms and other requirements. Cost regulation is the basic requirements to ensure that the use of funds is reasonable and effective. Good cost Regulation can contribute to the place of all materials, machinery and measures successfully, ensure quality and schedule of project, manage environment and safety better and reduce the Investment Risks.

(4)Project Safety Regulation Objective is the Guarantee

Personal safety is the human security for the work in an orderly manner. Security of property is the material guarantee for all work in an orderly manner. Scientific and reasonable safety regulation can ensure the progress of the work smooth, create a good working environment, cut back unexpected 
economic losses and reduce the incidence of risk. So that the project can be completed on schedule, and the quality can be guaranteed.

Project Green Regulation Objective is the Undamental

Sustainable development, the harmonious development of man and nature, green is the fundamental requirement for work in all and the national mandatory requirements for project construction. Positive green regulation can create a good working environment, reduce and eliminate the interference to external environment, ensure quality and schedule of project, save resources, construct safely and reduce Environmental Risks.

(4)Project Risk Regulation Objective is the Foundation

Project quality, schedule, cost, and safety, green regulation involve risks inherently. At the same time, there are many external social risks caused by international situation, national policy, cultural traditions, public events and construction itself. Proactive risk regulation can eliminate hidden quality problems, prevent schedule delays, reduce economic losses, ensure personal and property safety, reduce the degree of environmental damage and promote social stability.

Six objectives system of project regulation considers the effect of six objectives to project. This system can achieve integrated management, get good economic, environmental and social benefits, and implement scientific and standardized management.

\subsection{Monitoring Systems of Project Regulation Objective System}

To achieve the best management effectiveness, it requires not only comprehensive management objectives, but also sophisticated monitoring systems, including national regulations, standards, technical measures and procedural requirements. Surveillance measures of six regulation objectives showed in Table 1.

Table 1 Surveillance measures of six regulation objectives

\begin{tabular}{cl}
\hline Objective & \multicolumn{3}{c}{ Surveillance measures } \\
\hline \multirow{3}{*}{ Quality } & "People's Republic of China Construction Law", "Construction Quality Testing \\
& management approach", "Roof Project Quality Acceptance", and other laws, \\
& measures, specifications, and other national, local, corporate documents, etc. \\
& "People's Republic of China Construction Law", "The implementation of mandatory \\
Schedule & standards for construction supervision norms", and other laws, measures, \\
& specifications, and other national, local, corporate documents, etc. \\
& "People's Republic of China Construction Law", "The implementation of mandatory \\
Cost & standards for construction supervision norms", and other laws, measures, \\
& specifications, and other national, local, corporate documents, etc. \\
& "Construction Safety Management Regulations", "Construction work safety \\
Safety & supervision and management regulations", "Construction safety inspection \\
& standards", and other laws, measures, specifications, and other national, local, \\
& corporate documents, etc. \\
& "People's Republic of China Environmental Protection Law", "Construction Project \\
Green & Environmental Protection Management Measures","Construction Project \\
& Environmental Protection Management Regulations", and other laws, measures, \\
& specifications, and other national, local, corporate documents, etc. \\
& "Railway Tunnel risk assessment and management Interim Provisions", "Urban Rail \\
& Transit underground project construction risk management practices", \\
Risk & "Medium-sized hydropower project construction risk management practices", and \\
& other laws, measures, specifications, and other national, local, corporate documents, \\
etc. & \\
\hline
\end{tabular}




\subsection{Construction of Project Regulation Objective System Based on Multi-barrel Model}

Six objectives of project regulation are complementary, and its monitoring system is indispensable. Only in the way of combining six objectives and monitoring systems organically, can build a scientific and standardized Project Regulation Objective System. Quality objective is the key. Schedule objective is the main line. Cost objective is the requirement. Safety objective is the guarantee. Green objectives is the undamental. Risk objectives is the foundation. Monitoring systems is the protection of the implementation of the six objectives. According to the relationship among quality, schedule, cost, safety, green and risk objective and monitoring systems, we can build Project Regulation Objective System based on Multi-barrel Model, as shown in Figure 2.

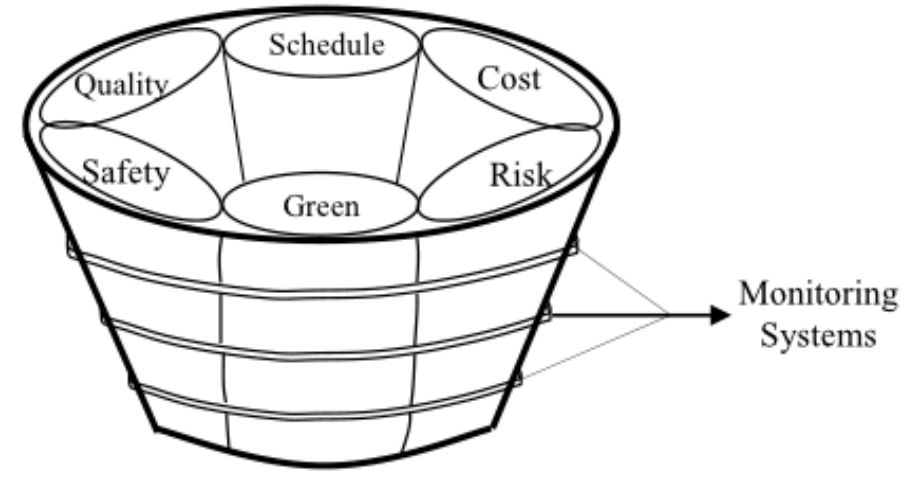

Fig. 2 Project Regulation Objective System based on Multi-barrel Model

Quality, schedule, cost, safety, green and risk objectives have their own internal indicators which constitute single objective keg. Six objective kegs and barrel hoop which plays a supervisory role constitutes Multi-barrel Model of Project Regulation Objective System. Six objective kegs can be seen as the sheet of Project Regulation Objective System Vats. Monitoring systems can be seen as barrel hoop of Project Regulation Objective System Vats.

Six objectives are equally important, and the importance in Multi-barrel Models is same. Each sub-objective is not isolated, and there is a necessary connection among them, such as quality problems may develop into security or risk issues. Thus, in addition to meeting the sub-objective own requirements, we should attach great importance to significant correlation among the various objectives and its direct impact on each other when determine the concept and evaluated content of sub-objective. In this context, we can say that the water capacity of Multi-barrel Model depends on the barrel whose water capacity is minimal, and each small bucket's water capacity depends on internal structure whose index value is worst.

Functioning smooth of the Multi-barrel Model needs reinforcement guarantee of barrel hoop (monitoring system). Putting forward the six project management objectives simply cannot ensure collaborative management to six goals. Only in the way of taking monitoring measures, can achieve the functioning of Multi-barrel Model of Project Regulation Objective System smooth.

\section{Application of Project Regulation Objective System}

Regional economic, policy, natural and social environment where project is located is different, so it has its own characteristics and management priorities in the actual development and construction. Only according to local conditions, can ensure project to the complete successfully.

\subsection{Project Overview}

Xi'an-Tongchuan Extension Expressway Project (Hereinafter referred Xitong Expressway) is an important section of Baotou-Maoming Expressway which was planned by country. The road runs through the northern Shaanxi, Guanzhong and South Shaanxi, and it is the important sections of "Two rings six radiation three vertical and seven horizontal" in Shaanxi planning. Xitong Expressway total length of $62 \mathrm{~km}, 2008$ started and 2011 opened to traffic. 


\subsection{Regulation Overview}

The responsible departments of Xitong Expressway kept the attention on quality, schedule, cost regulation objective, while strengthening safety objective, introducing environmental supervision and exploring risk objective. Shanxi Gaosu Consulting Ltd. assumed safety regulation objective and was responsible for personal health and property safety. Environmental Engineering Research Institute of Chang'an University and Northwest Water Resources and Hydropower Project Construction Supervision Center assumed green objective and were responsible for water, sound, air, solid, social environment, soil and water conservation. Project Department which is set up in each of the tenders was responsible for quality, schedule, and cost. Department of Environmental Protection which was specifically set up strive to achieve green goals by taking organizational and technical measures. The responsible departments analyzed risk objective and constructed corresponding monitoring system.

Applications of Project Regulation Objective System in Xitong Expressway can be seen in Table 2.

Table 2 Applications of Project Regulation Objective System in Xitong Expressway

\begin{tabular}{|c|c|c|c|}
\hline Objective & Degree of attention & Monitoring measures & Applications \\
\hline Quality & Emphasis & $\begin{array}{c}\text { Laws, measures, specifications and "Highway Code", } \\
\text { "Highway Project Quality management approach", } \\
\text { "Highway Project Quality Supervision regulations" } \\
\text { and so on }\end{array}$ & $\begin{array}{c}\text { basic } \\
\text { implementation }\end{array}$ \\
\hline Schedule & Very concerned & $\begin{array}{l}\text { Laws, measures, specifications, and other national, } \\
\text { local, corporate documents, etc. }\end{array}$ & $\begin{array}{c}\text { Full } \\
\text { implementation }\end{array}$ \\
\hline Cost & Very concerned & $\begin{array}{l}\text { laws, measures, specifications, and other national, } \\
\text { local, corporate documents, etc. }\end{array}$ & $\begin{array}{l}\text { General } \\
\text { implementation }\end{array}$ \\
\hline Safety & Emphasis & $\begin{array}{c}\text { Laws, measures, specifications and "Road and Water } \\
\text { Project Production Safety Supervision and } \\
\text { Management Measures", "Highway and Waterway } \\
\text { construction enterprises safety production } \\
\text { management personnel assessment management } \\
\text { approach" and so on. }\end{array}$ & $\begin{array}{c}\text { General } \\
\text { implementation }\end{array}$ \\
\hline Green & General emphasis & $\begin{array}{l}\text { Laws, measures, specifications, and other national, } \\
\text { local, corporate documents, etc. }\end{array}$ & $\begin{array}{c}\text { Partial } \\
\text { implementation }\end{array}$ \\
\hline Risk & General emphasis & $\begin{array}{l}\text { Laws, measures, specifications, and other national, } \\
\text { local, corporate documents, etc. }\end{array}$ & $\begin{array}{l}\text { Partial } \\
\text { implementation }\end{array}$ \\
\hline
\end{tabular}

\subsection{Application Analysis}

We can see from Table 2, Xitong Expressway considered the six objectives and monitoring systems, so it built Multi-barrel Model successfully. Xitong Expressway was built based on original Xitong Expressway, so it has relevant experience in many aspects. In management of this extension project, quality, schedule, cost was still the most important objective, so their level of implementation is high. Requirements of safety objective was improving, and its management has been a certain degree of protection, so its level of implementation was also high. Green and risk objectives received attention only in recent years, and its content, requirements and system are still not perfect, so they may became "short board" .

For "short board", Xitong expressway has taken appropriate regulatory measures. For green objective, supervisor set up a special department in charge of Environment Monitoring, and Environmental Engineering Research Institute of Chang'an University and Northwest Water Resources and Hydropower Project Construction Supervision Center distinguished were responsible for environmental management. For risk objective, supervisor surveyed environment along in detail, discussed various possible risks regularly and took precautions timely. At the same time, supervisor attached great importance to the linkages among six objectives. Therefore, they regulated six goals together and achieved good management effectiveness which provided good protection for construction. For monitoring systems, managers formulated relevant regulatory regime in accordance with our laws, regulations, scheme regulations and specifications and so on. 
On the basis of the above work, Xitong expressway completed successfully in a safe, orderly and green environment. After Xitong expressway opened to traffic in 2012, Northern Shaanxi, Guanzhong, South Shaanxi three major economic zones has been developing quickly.

\section{Summary}

The paper analyzes the limitations of current project management objectives and found that management of personal and property safety, green construction and risk control is relatively weak which is not conducive to optimum management.

The paper introduces the safety, green and risk objective and builds Project Management Objective System which includes quality, schedule, cost, safety, green and risk objective.

Six management objectives correspond to six regulation objectives. Six objectives are related closely and cannot exist independently. Quality regulation objective is a key. Schedule regulation objective is the main line. Cost regulation objective is the requirement. Safety regulation objective is the guarantee. Green regulation objective is the undamental. Risk regulation objective is the foundation.

Simultaneously, there requires a strong oversight system to achieve above six objectives. The paper constructs sophisticated monitoring systems, including our regulations, standards, technical measures and procedural requirements.

A scientific and standardized Project Regulation Objective System is built by combining six objectives and monitoring systems based on Multi-barrel Model. This model is a scientific and rational system which contains not only the content of six regulation objectives but also corresponding monitoring system.

Project Regulation Objective System was applied to Xitong Expressway Extension Project. Practice has proved that, this model has a good effect and is an effective regulation system.

\section{References}

[1]. Wei Zhou, Shuhong Ma.Adaptability of Highway Transportation and Economic Development Based Barrel Theory.Chinese Journal of Highway. Vol. 16 (2003) No. 16, p. 77-82.

[2]. Jianwen $\mathrm{Wu}$, Tao Wang,Lingkui Xu,Chunwu Li.Assessment scheme of Information security quantitative Based on Multi-barrel Model.Computer Application Research.Vol. 5 (2011) No. 28, p. 1914-1917.

[3]. Hong Ren,Yonggang Yan.New Ideas of Three Basic Objectives of Project Management. Scientific and Technological Progress and Countermeasures.Vol. 10 (2008) No. 25, p. 63-66.

[4]. Dongliang Yuan,Delong Xu,Huimin Li.Research on Target Control of Construction Project[J]. Ournal of Xi'an University of Architecture And Technology (Natural Science Edition).Vol. 1 (2010) No. 42, p.100-104.

[5]. Mei Lu,Yang Liu,Ting Jin,Yingying Sun.Project target management based on SD and fuzzy control[J].Ournal of Xi'an University Of Architecture And Technology(Natural Science Edition).Vol. 3 (2012) No. 44, p.400-405.

[6]. Ning Lu,Lin Li,Yanping Xie.Research on Earned Value Method of Safety Management in Construction Engineering Project[J].China Safety Science Journal.Vol. 3 (2013) No. 23, p.145-149.

[7]. Xiaolin Dong,Yunfeng Bai,Wang Pan,Guanghua Cao.Research on the Design of Environmental Protection Scheme for Project Construction Organization[J].Journal of Architectural Science and engineering.Vol. 2 (2013) No. 30, p.121-126.

[8]. Yuqing Yuan,Xiaolin Dong.Environmental Management During Construction Period of Highway Construction Project[J].Journal of Chang'an University:Social Science Edition.Vol. 1 (2006) No. 8, p.5-9.

[9]. Lin Yang,Exiang Luo.Research on Social Risk Evaluation Index System of Major Projects[J]. Science and Technology and Management.Vol. 2 (2010) No. 12, p.43-46. 